\title{
FILSAFAT ORDINARY LANGUAGE DAN PEMBELAJARAN BAHASA
}

\author{
Nurlaila \\ Program Studi Pendidikan Bahasa Arab Sekolah Tinggi Agama Islam Negeri Batusangkar \\ Korespondensi: Jl. Sawah Tabing No. 10 Rambatan Batusangkar, Sumatera Barat \\ e-mail: nur.laila304@gmail.com
}

\begin{abstract}
Ordinary language philosophy was one of the streams of analical language philosophies that had layed on how language was used. This became basic principle in studying pragmatic in lingusitic study. The idea of ordinary language about the pragmatic approach in learning language oriented to create the students' communication ability that was appropriate with the context where the communication happened. It was because learning language means leaning communication and language as a tool of communication that could be used in various function and situation.
\end{abstract}

Kata kunci: filsafat, ordinary language, pragmatik, bahasa, pembelajaran

\section{PENDAHULUAN}

$\mathrm{S}$ etiap praktik pendidikan memiliki landasan filosofis yang akan menentukan arah dan pelaksanaan pendidikan tersebut. Menurut Suyitno (2009: 7), landasan filosofis pendidikan adalah asumsi filosofis yang dijadikan titik tolak dalam rangka studi dan praktik pendidikan. Sebagaimana dipahami, bahwa dalam pendidikan mesti terdapat momen studi pendidikan dan momen praktik pendidikan, maka melalui studi pendidikan antara lain kita akan memperoleh pemahaman tentang landasanlandasan pendidikan, yang akan dijadikan titik tolak praktik pendidikan. Dengan demikian, landasan filosofis pendidikan sebagai hasil studi pendidikan tersebut dapat dijadikan titik tolak dalam rangka studi pendidikan yang bersifat filsafiah, yaitu pendekatan yang lebih komprehensif, spekulatif, dan normatif.

Filsafat pendidikan dapat terwujud dengan menarik garis linear antara filsafat dan pendidikan. Dalam hal ini, filsafat seolah-olah dijabarkan secara langsung ke dalam pendidikan, dengan maksud untuk menghasilkan konsep pendidikan yang berasal dari suatu cabang atau aliran filsafat (Barnadib, 1994: 58). Sementara filsafat pendidikan bahasa merupakan sinerji antara filsafat pendidikan dan filsafat bahasa. Filsafat pendidikan adalah teori yang mendasari alam pikiran hal ihwal pendidikan atau suatu kegiatan pendidikan. Sedangkan filsafat bahasa berkaitan dengan pertanyaan-pertanyaan seperti hakikat dan fungsi bahasa, hubungan bahasa dan realitas, jenis-jenis sistem simbol, dan dasar-dasar untuk mengevaluasi sistem bahasa. Dengan demikian filsafat pendidikan bahasa adalah teori yang mendasari alam pikiran manusia ihwal pendidikan bahasa atau suatu kegiatan pendidikan bahasa. Berdasarkan filsafat pendidikan bahasa ini maka berkembanglah teori-teori, pendekatan-pendekatan, metode-metode, dan teknik- 
teknik mengajar bahasa. Setiap kebijakan instruksional guru dalam kelas dapat ditelusuri ke hulu pemikirannya, yakni filsafat pendidikan bahasa yang menjadi kepercayaannya (Alwasilah, 2009: 1416).

Pendidikan bahasa di Indonesia bahasa nasional, bahasa daerah ataupun bahasa asing- dilaksanakan sesuai dengan filsafat yang dianut oleh pihakpihak yang terlibat di dalamnya. Artikel ini akan menguraikan tentang salah satu landasan filosofis praktik pendidikan bahasa yaitufilsafat ordinary language, dan mengaitkan gagasan-gagasan dalam filsafat tersebut dengan kegiatan pembelajaran bahasa, khususnya yang menggunakan pendekatan pragmatik.

\section{FILSAFAT ANALITIK BAHASA}

Era pasca modern dimulai pada abad ke-19 dan 20 dengan timbulnya berbagai aliran yang berpengaruh seperti positivisme, marxisme, eksistensialisme, pragmatisme, neo kantianisme, neo tomisme dan fenomenologi. Aliran-aliran ini sangat terikat oleh keadaan negara maupun lingkungan bahasa, sehingga dalam perkembangan terakhir lahirlah filsafat analitik yang lahir sejak tahun 1950 (Surajiyo, 2005: 158-163).

Menurt Kaelan (2002: 77-79), diakui oleh kalangan filsuf dan historian, bahwa filsafat analitik bahasa sulit ditentukan batasan pengertiannya, karena dasar-dasar filosofisnya yang cukup rumit, padat, dan sangat beragam. Secara terminologi istilah filsafat analitik bahasa baru dikenal dan populer pada abad XX, meskipun berdasarkan isi materi dan metodenya filsafat analitik bahasa itu telah berkembang sejak lama bahkan sejak zaman Yunani, yaitu sejak zaman pra Socrates. Pada zaman Socrates, bahasa bahkan menjadi pusat perhatian filsafat ketika retorika menjadi medium utama dalam dialog filosofis. Kekhusukan manusia dalam mengagung- kan sang Maha Kuasa pada abad pertengahan juga diungkapkannnya melalui ungkapan manusiawi yaitu bahasa. Menurut Hidayat (2009: 13), filsafat bahasa jika dilihat sebagai sebuah ilmu, adalah kumpulan hasil pikiran para filosof mengenai hakikat bahasa yang disusun secara sistematis untuk dipelajari dengan metode tertentu. Sedangkan jika diartikan sebagai metode berpikir, filsafat bahasa adalah metode berpikir secara mendalam (radik), logis, dan universal mengenai hakikat bahasa.

Menurut Noddings (1998: 34), filsafat analitik dalam semua bentuknya menyatakan untuk melakukan analisis dan klarifikasi, seperti bentuk filsafat analitik yang dikembangkan oleh Russel yang berkonsentrasi pada hubungan antara bahasa dan realitas. Seorang filosof analitik mungkin akan menganalisis konsep pengajaran atau pendidikan. Dalam pelaksanaannya, filosof analitik akan mencoba memisahkan konsep tersebut dari segala sesuatu yang berhubungan eratdengannya, dan perhatian serius akan dicurahkan pada beragam konteks linguistik dimana konsep tersebut muncul.

Ciri yang menonjol dari filsafat analitik adalah netralitas, seperti yang dinyatakan oleh Wittgenstein bahwa filsafat "leaves everything as it is". Oleh karena itu, philosophy does not change the world; it just makes the world clearer (Noddings, 1998: 34). Dengan demikian filsafat analitik berbeda dengan filsafat-filsafat sebelumnya, ciri khas filsafat analitik adalah memberikan penjelasan terhadap konsep yang ada sehingga menjadi lebih clear, bukan mengubah konsep yang telah ada menjadi konsep yang lain.

Pandangan di atas didukung oleh definisiyang diberikan oleh Chapman \& Routledge (2009: 11), bahwa sebuah kebenaran analitik adalah sebuah pernyataan (proposisi) yang benar sematamata berdasarkan atasmakna dari 
komponen kata-katanya (atau konsepkonsep).

Banyak filosof pendidikan sekarang ini yang menganggap diri mereka sebagai filosof analitik. Mereka sibuk melakukan analisis konseptual atau kontekstual. Filsafat-filsafat pendidikan era 1950-an, 1960-an, dan 1970-an juga banyak yang melakukan analisis bahasa dan konsep-konsep pendidikan. Motivasi dasarnya adalah suatu keyakinan bahwa ordinary language (analisis konseptual) menyimpan sebuah makna yang bernilai tinggi yang hingga saat itu belum terungkap karena belum dianalisa (Noddings, 1998: 34-35).

\section{FILSAFAT ORDINARY LANGUAGE DAN PRAGMATIK}

Salah satu aliran filsafat analitik bahasa adalah ordinary language philosophy. Pemikiran filsafat Wittgenstein periode IImerupakan suatu bentuk filsafat ordinary language. Konsep pemikiran filsafat Wittgenstein periode II tertuang dalam suatu karyanya yang berjudul Philosophical Investigations yang memiliki corak yang berlainan bahkan bertolak belakang dengan pemikirannya dalam Tractatus (periode I) yang mendasarkan pada semantik dan memiliki formulasi logika. Pada karyanya yang kedua ini, Wittgenstein menyadari bahwa bahasa yang diformulasikan melalui logika sebenarnya sangat tidak mungkin untuk dikembangkan dalam filsafat, sehingga dalam buku Philosophical Investigations ini ia mengkritik bahkan menolak pendapatnya yang pertama. Buku karya Wittgenstein ini berisi banyak tesis dan pernyataanpernyataan, ada yang telah dikembangkan lebih lanjut dan terdapat pula ungkapan-ungkapan yang masih orisinil (Kaelan, 2002: 145).

Salah satu tesis pokok dari pandangan Wittgenstein (II) adalah bahwa 'makna sebuah kata adalah pengguna- annya dalam bahasa, dan makna bahasa itu adalah penggunaannya di dalam hidup'. Pandangan Wittgenstein (II) ini lebih menekankan pada aspek pragmatik bahasa atau lebih meletakkan bahasa dalam fungsinya sebagai alat komunikasi dalam kehidupan manusia. Bahasa tidak hanya memiliki satu struktur logis saja melainkan segi penggunaannya dalam hidup manusia yang bersifat kompleks yang meliputi berbagai bidang kehidupan (Kaelan, 2002: 145-146). Dengan demikian, filsafat ordinary language oleh Wittgenstein lebih menekankan pada aspek pragmatik bahasa, yaitu bagaimana penggunaan suatu istilah atau ungkapan dapat mengandung makna.

Dengan mengakui fungsi-fungsi bahasa yang bermacam-macam, Wittgenstein mengubah tugas filsafat. Berlainan dengan kelompok positivis, ia tidak menolak pernyataan-pernyataan metafisika secara mutlak. Kita membawa kembali kata-kata 'dari pemakaian metafisika kepada pemakaian sehari-hari'. Dalam filsafat kita tidak menarik kesimpulan. Filsafat hanya menyatakan apa yang diterima oleh setiap orang. Dengan begitu filsafat tidak memberikan tambahan informasi baru, tetapi me-nambah jelas dengan lukisan yang teliti dari bahasa (Titus dkk., 1984: 372).

Berdasarkan pemikiran-pemikirannya, Wittgenstein membuka suatu cakrawala baru dalam berfilsafat yaitu tidak lagi didasarkan atas bahasa yang memiliki struktur logika yang ketat, tidak lagi didasarkan atas logika formal dan matematis, melainkan mendasarkan kepada bahasa sehari-hari, yaitu bahasa yang dipakai dalam kehidupan seharihari (ordinary language) (Kaelan, 2002: 146).

Dalam analisis ordinary language, penekanannya adalah bagaimana bahasa digunakan. Tentu saja, analisis ini digunakan untuk menganalisis konsepkonsep, sehingga istilah conceptual analysis and ordinary language 
philosophy sering digunakan dalam satu arti (Noddings, 1998: 34).

Ide bahwa semuaproses pemakaian kata bisa dilihat sebagai semacam permainan, pertama kali diperkenalkan oleh Ludwig Wittgenstein pada tahun 1953 dengan nosinya tentang language game. Tujuan penggunaan kata 'game' adalah untuk menggarisbawahi fakta bahwa berbahasa adalah bagian dari suatu aktifitas, a way of life (Bara, 2010: 93). Dengan demikian, language game mengacu pada fakta penggunaan bahasa, dimana bahasa merupakan sebagian dari kegiatan atau merupakan a way of life. Bahasa sesungguhnya adalah alat permainan kepentingan. Melalui penggunaan bahasa akan ditemukan beragam kepentingan yang tersurat dan tersirat, individu atau kelompok memanfaatkan bahasa untuk menunjukkan atau menyembunyikan kepentingan tersebut.

Beragam permainan bahasa dapat ditemukan dalam kehidupan sehari-hari, seperti memberikan perintah dan mentaatinya, menguraikan keadaan, memberikan penjelasan, melaporkan peristiwa, mengarang cerita, membuat tekateki, bersenda gurau, bertanya dan menjawab, berterima kasih, mengucapkan salam, dan masih banyak lagi ragam bahasa lainnya.

Pemikiran-pemikiran Wittgenstein di atas menjadi landasan bagi studi pragmatik. Mey (dalam Subuki, 2006: 1) menjelaskan bahwa pragmatik tumbuh dan berkembang dari empat kecenderungan atau tradisi, yaitu: (1) kecenderungan antisintaksisme; (2) kecenderungan sosial-kritis; (3) tradisi filsafat; dan (4) tradisi etnometodologi. Tradisi filsafat yang dimaksudkan oleh Mey di sinidipelopori salah satunya oleh Wittgenstein bersama beberapa pakar lainnya.

Kajian-kajian Wittgenstein menekankan pada penggunaan bahasa yang mengandung maknadan menempatkan bahasa sebagai sarana komunikasibagi manusia dalam berhubungan dengan sesamanya. Pemikiran-pemikiran inilah yang kemudian menjadi salah satu landasan bagi studi pragmatik dalam linguistik.

\section{GAGASAN FILSAFAT ORDINARY LANGUAGE DALAM PEMBE- LAJARAN BAHASA}

Pada hakikatnya, belajar bahasa adalah belajar berkomunikasi. Oleh karena itu pembelajaran bahasa harus diarahkan untuk meningkatkan kemampuan dalam berkomunikasi, baik secara lisan maupun tulisan. Bahasa sebagai sarana komunikasi digunakan dalam bermacam-macam fungsi dan situasi, oleh karena itu bahasa harus disajikan dalam konteks yang bermakna, tidak dalam bentuk kalimat yang dibuatbuat atau situasi yang tidak pernah dialami oleh siswa.

Agar pembelajaran bahasa dapat mencapai tujuan di atas, diperlukan suatu pendekatan yaitu pendekatan pragmatik. Karena pendekatan dalam pembelajaran bahasa mengacu pada asumsi atau aksioma tentang apa itu bahasa dan bagaimana belajar bahasa berlangsung, pendekatan pragmatik berisi asumsiasumsi pragmatik tentang apa itu bahasa dan bagaimana bahasa seharusnya dibelajarkan.

Yule (1996: 3) mengemukakan salah satu definisi pragmatik yaitu bidang yang mengkaji makna yang dikomunikasikan atau terkomunikasikan oleh pembicara. Sementara menurut Levinson (dalam Nababan, 1987: 3), pragmatik ialah kajian dari hubungan antara bahasa dan konteks yang mendasari penjelasan pengertian bahasa. Berdasarkan dua definisi di atas, dapat disimpulkan bahwa pragmatikadalah bidang yang mengkaji tentangmakna yang dikomunikasikan melalui bahasa sesuai konteksnya. 
Dengan demikian, pembelajaran bahasa dengan pendekatan pragmatik berorientasi pada pembentukan kemampuan komunikatif siswa sesuai dengan konteks dimana komunikasi tersebut berlangsung.Chomsky (1965: 4) menyebutnya dengan linguistic performance yaituthe actual use of languagein concrete situations.

Dalam pragmatik, pembelajaran bahasa tidak didasarkan pada struktur melainkan didasarkan pada pemakaian bahasa sesuai konteksnya dalam komunikasi sehari. Kondisi praktis tindak komunikasi menjadi pijakan utama dalam pragmatik. Prinsip-prinsip komunikatif sangat diperhatikan oleh pragmatik, oleh karena itulah pemakaian istilah pragmatik dan komunikatif sering digunakansecara bergantian untuk maksud yang sama.

Menurut Arsyad (1997: 317), pragmatik mengkaji bahasa lebih jauh pada aspek keterampilan menggunakan bahasa untuk berkomunikasi praktis dalam segala situasi yang mendasari interaksi kebahasaan antara manusia sebagai anggota masyarakat. Dengan demikian, terlihat jelas bahwa orientasi pengkajian pragmatik adalah pada suatu komunikasi praktis, di mana pada tataran praktis, muncul berbagai faktor diluar bahasa yang turut memberi makna dalam proses komunikasi tersebut. Dan kemampuan untuk mengkaji hal-hal di luar bahasa tentu akan sangat membantu siswa dalam mengaplikasikan kompetensi berbahasa yang dimilikinya secara praktis dalam kondisi senyatanya.

Menurut Leech (1993:19), aspekaspek pragmatik adalah sebagai berikut:

1. Penutur dan lawan tutur. Konsep penutur dan lawan tutur ini juga mencakup penulis dan pembaca bila tuturan yang bersangkutan dikomunikasikan dalam bentuk tulisan. Aspekaspek tersebut adalah usia, latar belakang sosial ekonomi, jenis ke- lamin, tingkat keakraban, dan sebagainya.

2. Konteks tuturan. Konteks di sini meliputi semua latar belakang pengetahuan yang diperkirakan dimiliki dan disetujui bersama oleh penutur dan lawan tutur, serta yang menunjang interpretasi lawan tutur terhadap apa yang dimaksud penutur dengan suatu ucapan tertentu.

3. Tujuan tuturan. Setiap situasi tuturan atau ucapan tentu mengandung maksud dan tujuan tertentu pula. Kedua belah pihak yaitu penutur dan lawan tutur terlibat dalam suatu kegiatan yang berorientasi pada tujuan tertentu.

4. Tuturan sebagai bentuk tindakan dan kegiatan tindak tutur. Dalam pragmatik ucapan dianggap sebagai suatu bentuk kegiatan yaitu kegiatan tindak ujar. Pragmatik menggarap tindaktindak verbal atau performansi-performansi yang berlangsung di dalam situasi-situasi khusus dalam waktu tertentu.

5. Tuturan sebagai produk tindak verbal. Dalam pragmatik tuturan mengacu kepada produk suatu tindak verbal, dan bukan hanya pada tindak verbalnya itu sendiri. Jadi yang dikaji oleh pragmatik bukan hanya tindak ilokusi, tetapi juga makna atau kekuatan ilokusinya.

Agar dapat memahami aspekaspek di atas, dalam pendekatan pragmatik, guru berusaha memberikan kesempatan kepada siswa untuk mengembangkan keterampilan berbahasa di dalam konteks nyata dan situasi yang kompleks. Melalui proses ini, diharapkan mampu membawa siswa ke dalam situasi dan konteks berbahasa yang sesungguhnya sehingga keterampilan berbahasa melekat pada diri siswa.

Menurut Patzam (2011), implikasi pendekatan pragmatik dalam pengajaran bahasa adalah: 
1. Dalam pengajaran dengan pendekatan pragmatik tujuan pengajaran yang harus dicapai adalah dimilikinya kemampuan komunikatif (use of linguistic elements).

2. Pengajaran yang berupa satuan-satuan lingual itu harus disajikan di dalam suatu konteks komunikasi yang riil, bukan dibuat-buat.

3. Karena di dalam konteks komunikasi yang riil satuan-satuan lingual itu tidak tersaji secara sistematis, maka tekanan penyajian perlu diprioritaskan pada kadar keseringan kemunculan satuan-satuan lingual di dalam suatu konteks, diisyaratkan bahwa penekanan penyajian pada urutanurutan satuan lingual berdasarkan temuan linguistik menjadi kurang penting.

Dengan demikian, seleksi dan urutan bahan pembelajaran perlu dilakukan dengan mempertimbangkan skala prioritas kebutuhan terhadap materi dalam komunikasi. Materi tersebut disajikan dalam konteks komunikasi nyata sehingga dapat mengantarkan

\section{DAFTAR RUJUKAN}

Alwasilah, A. Chaidar. 2009. Filsafat Bahasa dan Pendidikan. Bandung: PT Remaja Rosdakarya.

Bara, Bruno G. 2010. Cognitive pragmatics. Cambride: Library of Congress.

Barnadib, Imam.1994. Hand Out Filsafat Pendidikan. Yogyakarta: PPs UGM

Chapman, Siobhan \& Routledge, Christopher (Eds). 2009. Key Ideas in Linguistics and the Philosophy of Language. Edinburgh: Edinburgh University Press.

Chomsky, Noam. 1965. Aspects of the theory of syntax. Cambridge, MA: MIT Press. siswa memiliki kemampuan komunikatif, yang pada akhirnya diharapkan siswa mampu berkomunikasi dan berinteraksi sosial dalam lingkungannya secara baik.

\section{PENUTUP}

Berdasarkan paparan di atas, dapat ditarik suatu kesimpulan bahwa pembelajaran bahasa yang diorientasikan pada tataran praktis tindak komunikasi akan sangat diperlukan bagi peserta didik. Dalam hal ini, gagasan filsafat ordinary languagetentang pendekatan pragmatik sangat membantu dalam mengarahkan proses pembelajaran bahasa yang dilakukan, terutama pada tataran pendidikan formal atau sekolah. Dengan pendekatan pragmatik dalam pembelajaran bahasa, diharapkan siswa akan lebih dapat mengaktualisasikan kemampuan berbahasa yang dimiliki sesuai dengan konteksnya dalam kehidupan sehari-hari di tengah masyarakat.

Hidayat, Asep Ahmad. 2009. Filsafat Bahasa. Bandung: PT Remaja Rosdakarya

Kaelan M.S. 2002. Filsafat Bahasa Masalah dan Perkembangannya. Yogyakarta: Paradigma

Leech, Geoffrey. 1993. Prinsip-Prinsip Pragmatik. Diterjemahkan oleh M.D.D. Oka. Jakarta: Indonesia University Press

Nababan, P.W.J. 1987. Ilmu Pragmatik (Teori dan Penerapannya). Jakarta: Depdiknas.

Noddings, Nel (Lee L. Jacks). 1998. Philosophy of Education.Colorado: Westview Press. 
Patzam, Julizar. 2011. Pragmatik Bahasa Indonesia, (Online), http://jpzx1.

blogspot.com/2011/01/pragmatikbahasa-indonesia.html. diakses 7 Januari 2013.

Subuki, Makyun. 2006. Mengapa Pragmatik Perlu Dipelajari dalam Program Studi Linguistik?, (Online), http://www.scribd.com/doc/14548085/p ragmatik. diakses 7 Januari 2013.

Surajiyo. 2005. Ilmu Filsafat Suatu Pengantar. Jakarta: Bumi Aksara
Suyitno, Y. 2009.Landasan Filosofis Pendidikan.Bandung: FP UPI

Titus, Harold H. dkk. 1984. Persoalanpersoalan Filsafat. Diterjemahkan oleh H.M. Rasyidi. Jakarta: Bulan Bintang.

Yule, George. 1996. Pragmatik. Diterjemahkan oleh Indah Fajar W dan Rombe Mustajab. Yogyakarta: Pustaka Pelajar. 